\title{
BMJ
}

\section{Nurse led interventions to improve control of blood pressure in people with hypertension: systematic review and meta-analysis}

\author{
Christopher E Clark, clinical academic fellow, Lindsay F P Smith, senior clinical research fellow, Rod S Taylor, \\ professor in health services research, John L Campbell, professor of general practice and primary care
}

Primary Care Research Group, Institute of Health Services Research, Peninsula College of Medicine and Dentistry, St Luke's Campus, Exeter EX1 2LU Correspondence to: C E Clark christopher.clark@pms.ac.uk

Cite this as: $B M J$ 2010;341:c3995 doi:10.1136/bmj.c3995

\section{ABSTRACT}

Objective To review trials of nurse led interventions for hypertension in primary care to clarify the evidence base, establish whether nurse prescribing is an important intervention, and identify areas requiring further study. Design Systematic review and meta-analysis.

Data sources Ovid Medline, Cochrane Central Register of Controlled Trials, British Nursing Index, Cinahl, Embase, Database of Abstracts of Reviews of Effects, and the NHS Economic Evaluation Database.

Study selection Randomised controlled trials of nursing interventions for hypertension compared with usual care in adults.

Data extraction Systolic and diastolic blood pressure, percentages reaching target blood pressure, and percentages taking antihypertensive drugs. Intervention effects were calculated as relative risks or weighted mean differences, as appropriate, and sensitivity analysis by study quality was undertaken.

Data synthesis Compared with usual care, interventions that included a stepped treatment algorithm showed greater reductions in systolic blood pressure (weighted mean difference $-8.2 \mathrm{~mm} \mathrm{Hg}, 95 \%$ confidence interval -11.5 to -4.9$)$, nurse prescribing showed greater reductions in blood pressure (systolic $-8.9 \mathrm{~mm} \mathrm{Hg},-12.5$ to -5.3 and diastolic $-4.0 \mathrm{~mm} \mathrm{Hg},-5.3$ to -2.7 ), telephone monitoring showed higher achievement of blood pressure targets (relative risk 1.24, 95\% confidence interval 1.08 to 1.43), and community monitoring showed greater reductions in blood pressure (weighted mean difference, systolic $-4.8 \mathrm{~mm} \mathrm{Hg}, 95 \%$ confidence interval -7.0 to -2.7 and diastolic $-3.5 \mathrm{~mm} \mathrm{Hg},-4.5$ to -2.5 ).

Conclusions Nurse led interventions for hypertension require an algorithm to structure care. Evidence was found of improved outcomes with nurse prescribers from non-UK healthcare settings. Good quality evidence from UK primary health care is insufficient to support widespread employment of nurses in the management of hypertension within such healthcare systems.

\section{INTRODUCTION}

Essential hypertension is a major cause of cardiovascular morbidity. ${ }^{1}$ In 2003 the prevalence of hypertension in England was 32\% in men and 30\% in women. ${ }^{2}$ Since the prevalence of hypertension increases with age it is a growing public health problem in the Western world faced with ageing populations. ${ }^{3}$ The lowering of raised blood pressure in drug trials has been associated with a reduction in stroke of 35-40\%, heart attack of 20-25\%, and heart failure of over $50 \%{ }^{4}$ To achieve these benefits, aggressive and organised treatment to attain blood pressure targets is required, yet often contacts with health professionals do not trigger changes in antihypertensive therapy ${ }^{5}$; a phenomenon termed "clinical inertia." 6

Most patients require a combination of antihypertensive drugs to reach target blood pressure. Guidelines advocate logical drug combinations, ${ }^{7}$ and in England the National Institute for Health and Clinical Excellence has published a treatment algorithm for clinicians to follow. ${ }^{8}$ Hypertension is a condition almost entirely managed in primary care, and in the United Kingdom is an important component of the Quality and Outcomes Framework, which rewards practices for achievement of blood pressure standards set by the National Institute for Health and Clinical Excellence. ${ }^{9}$ Achievement between practices, however, varies considerably ${ }^{10}$ and knowledge of guidelines among general practitioners does not necessarily translate into their implementation. ${ }^{11}$

Doubt persists about how best to organise effective care and interventions to control hypertension by the primary care team. In 2005 a Cochrane review classified 56 trials of interventions into six categories: self monitoring, education of patients, education of health professionals, care led by health professionals (nurses or pharmacists), appointment reminder systems, and organisational interventions. The review concluded that an organised system of regular review allied to vigorous antihypertensive drug therapy significantly reduced blood pressure and that a stepped care approach for those with blood pressure above target was needed. ${ }^{12}$ Nurse or pharmacist led care was suggested to be a promising way forward but required further evaluation. Another review found that appropriately trained nurses can produce high quality care 
and good health outcomes for patients, equivalent to that achieved by doctors, with higher levels of patient satisfaction. ${ }^{13}$ Nurse led care is attractive as it has been associated with stricter adherence to protocols, improved prescribing in concordance with guidelines, more regular follow-up, and potentially lower healthcare costs. Without associated changes in models of prescribing, however, there seems to be little effect on blood pressure level..$^{14}$ At present the usual model of care is shared between general practitioners and practice nurses, with general practitioners prescribing. Our local survey of Devon and Somerset found that of 79 responding practices $(\mathrm{n}=182$; response rate $43 \%$ ) 53 were using this model, with only four using nurse led care, including nurse prescribing (unpublished observation). In the light of these uncertainties over models of care and whether blood pressure reduction with nurse led care can be achieved, we explored further the trial evidence for efficacy of nurse led interventions through a systematic review. To elucidate whether nurse prescribing is an important component of this complex intervention and to identify areas in need of further study, we reviewed the international evidence base for such an intervention and its applicability to primary care in the United Kingdom.

\section{METHODS}

We searched the published literature for randomised controlled trials that included an intervention delivered by nurses, nurse prescribers, or nurse practitioners designed to improve blood pressure, compared with usual care. The population of interest was adults aged 18 or over with newly diagnosed or established hypertension above the study target, irrespective of whether or not they were taking antihypertensive drugs. Primary outcome measures were systolic and diastolic blood pressure at the end of the study, changes in systolic and diastolic blood pressure compared with baseline, percentage of patients reaching target blood pressure, and percentage taking antihypertensive drugs. The secondary outcome was cost or cost effectiveness of interventions.

\section{Data sources and extraction}

We searched Ovid Medline, the Cochrane Central Register of Controlled Trials, British Nursing Index, Cinahl, Embase, Database of Abstracts of Reviews of Effects, and the NHS Economic Evaluation Database. Using a strategy modified from the previous review of 2005 we searched for randomised controlled trials in original English language and published between January 2003 and November 2009. ${ }^{12}$ We identified older citations from this review, hence the choice of cut-off date for the search (see web extra). We also corresponded with authors to identify missed citations.

Two authors (CEC, LFPS) independently selected potentially relevant studies by screening retrieved citations and abstracts. Trials assessed as definite or uncertain for inclusion were retrieved as full papers. Differences were resolved by discussion; arbitration from a third author (JLC) was planned but not required. Two authors (CEC, LFPS) independently extracted details of the studies and data using a standardised electronic form, with differences resolved by discussion. Risk of bias in the generation of the randomisation sequence, allocation concealment, and blinding (participants, carers, assessors) was assessed as adequate, uncertain, or inadequate using Cochrane criteria. ${ }^{15}$ One author (LFPS) checked the reference lists of all included studies for further potentially relevant citations, and two authors (CEC, LFPS) reviewed this list and agreed on further potentially relevant papers to retrieve in full. Searches were undertaken in June 2009 and repeated in November 2009 before final writing up.

\section{Statistical analysis}

Data were pooled and analysed using RevMan v5.0. ${ }^{16}$ We carried out separate analyses for each intervention and outcome measure compared with usual care. Intervention effects were calculated as relative risks with 95\% confidence intervals for dichotomous data. For continuous data we used a conservative random effects metaanalysis model to calculate mean differences and weighted mean differences with 95\% confidence intervals. When a study included more than one intervention group with a single comparator arm, we included both intervention groups and split the number of patients in the common comparator arm across the separate intervention arms. ${ }^{15}$ Where required we calculated standard deviations from standard errors or confidence intervals presented within papers. Heterogeneity was quantified using the $\mathrm{I}^{2}$ statistic and the $\chi^{2}$ test of heterogeneity. Using sensitivity analysis we explored heterogeneity by excluding single outlying results or restricting analysis to studies of good quality. We reported pooled data only when heterogeneity was not significant $(\mathrm{P}>0.05)$. Two authors (CEC, RST) reviewed the data from cluster randomised controlled trials and either extracted the data as presented when the authors were deemed to have taken account of cluster effects or first adjusted using a design factor, ${ }^{15}$ with intraclass correlation coefficients for systolic and diastolic blood pressure derived from cluster studies in primary care. ${ }^{17}$

\section{RESULTS}

Searches identified 1465 potential citations. A further 66 potential studies were identified from citations in retrieved papers. After initial screening of the titles and abstracts 71 full studies were assessed for possible inclusion in the review and 33 met the inclusion criteria (fig 1).

\section{Included studies}

Table 1 summarises the characteristics of the included studies. Seven cluster randomised controlled trials were randomised at practice ${ }^{18-23}$ or family level. ${ }^{24}$ Five described adjustment for clustering effects but two did not seem to have done so, therefore these were adjusted for cluster size. ${ }^{2324}$ One study used a two level nested design of interventions at provider and patient level; combined patient level outcomes 
were extracted where possible, or as separate intervention and control groups for each provider inter vention. ${ }^{25}$ Four studies had three arms. Three compared telephone monitoring and face to face nurse monitoring with usual care ${ }^{26-28}$ and outcomes were extracted as separate groups; one compared nurse and general practitioner interventions with usual care and only the nurse and control outcomes were extracted. ${ }^{21}$ The remaining randomised controlled trials were two armed studies randomised at individual patient level.

Interventions were categorised as nurse support delivered by either telephone (seven studies), ${ }^{25-31}$ community monitoring (defined as home or other nonhealthcare setting; eight studies), ${ }^{24632-37}$ or nurse led clinics. These were held in either primary care $(13$ studies) ${ }^{20-2327283538-43}$ or secondary care (six studies). ${ }^{4-49}$ One study used alternate sessions with nurses at home and in general practice.$^{50}$ Fourteen studies included a stepped treatment algorithm ${ }^{181921-243031353738404748}$ and nine included nurse prescribing in their protocol. ${ }^{243031353740444748}$

Although most of the studies recruited participants with hypertension, 11 also recruited participants with diabetes, ${ }^{18} 1922233136374446-48$ five with coronary heart disease, ${ }^{2021333950}$ and one the siblings of patients with coronary heart disease. ${ }^{24}$ Most studies recruited predominantly white participants. Four studied hypertension care provided to African Americans, ${ }^{24262940}$ three to Chinese, ${ }^{333446}$ two to South Asians, ${ }^{1923}$ one to American Indians, ${ }^{37}$ and two to mixed non-white populations. ${ }^{445}$ Thirty eight studies were excluded after review of the full paper (fig 1).

\section{Risk of bias in included studies}

Overall, study quality was moderate; random sequence generation was adequate in $70 \%(23 / 33)$ of studies, allocation concealment in 58\% (19/33), and blinding of data collection in 43\% (14/33); one study was described as an open (unblinded) randomised controlled trial. ${ }^{41}$ Thirteen studies were assessed as adequate in two of the three domains and adequate or unclear for the third. ${ }^{20222526293032-3440424648}$ These studies were defined as of "good quality" and were used for sensitivity analysis by study quality. Only three of these reported UK trials; one of patients with ischaemic heart disease and hypertension ${ }^{20}$ and two of people with diabetes and hypertension. ${ }^{2248}$ The method of blood pressure measurement was not described in 12 studies, ${ }^{19-24333942434647} \quad 10$ used automated monitors, ${ }^{1826-3036374448}$ and seven referred to authoritative guidelines for measurement. ${ }^{25323441444550}$

\section{Effects of interventions}

Pooling of data across different types of interventions was limited by noticeable statistical heterogeneity between studies, which was not explained by restriction to good quality studies. Consequently the results are presented as subgroup analyses by type of intervention (table 2). (See web extra for forest plots for all comparisons; summary statistics were omitted if

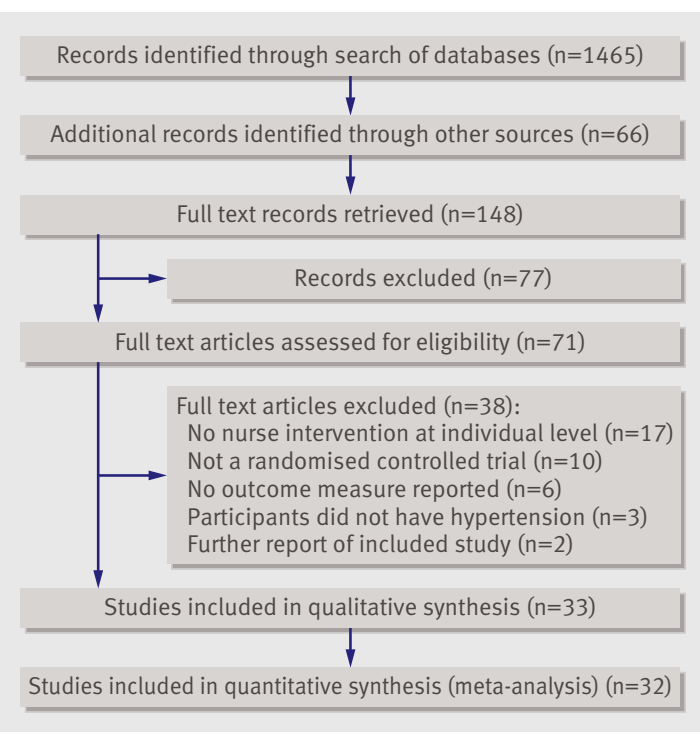

Fig 1| Flow of papers through study

significant heterogeneity was present; see table 2). One study did not report any estimates of variance and did not contribute data to the meta-analyses. ${ }^{42}$

\section{Use of a treatment algorithm}

Fourteen studies included a stepped treatment algorithm in their intervention ${ }^{18} 1921-243031353738404748$ and for nine it was the main focus of the inter vention. . $^{1921223537384748}$ Two studies of good quality $^{3040}$ showed greater magnitudes of reductions in blood pressure with the use of an algorithm compared with usual care: weighted mean difference, systolic $-9.7 \mathrm{~mm} \mathrm{Hg}$ (95\% confidence interval -14.0 . to $-5.4 \mathrm{~mm} \mathrm{Hg}$ ) and diastolic $-4.3 \mathrm{~mm} \mathrm{Hg}(-7.4$ to $-1.2 \mathrm{~mm} \mathrm{Hg}$ ). Pooling of all four studies also showed a greater magnitude of reduction in systolic blood pressure $(-8.2 \mathrm{~mm} \mathrm{Hg},-11.5 \text { to }-4.9 \text {; fig 2 })^{23303740}$ with the use of an algorithm compared with usual care.

Pooling of three good quality studies ${ }^{224048}$ showed no significant difference in achievement of study blood pressure targets in favour of an intervention including an algorithm (relative risk 1.09, 95\% confidence interval 0.93 to 1.27 ). Although a total of 10 studies reported this outcome, ${ }^{18192231353840424748}$ statistical and clinical heterogeneity between them was significant.

\section{Nurse prescribing}

Nine studies included nurse prescribing in their protocol; three in secondary care settings, ${ }^{44748}$ three using community interventions, ${ }^{243537}$ two using telephone monitoring, ${ }^{3031}$ and one based in primary care. ${ }^{40}$

Two good quality studies ${ }^{3040}$ showed greater magnitudes of blood pressure reductions for nurse prescribing than for usual care: weighted mean difference, systolic $-9.7 \mathrm{~mm} \mathrm{Hg}$ (95\% confidence interval -14.0 to -5.4$)$ and diastolic $-4.3 \mathrm{~mm} \mathrm{Hg}(-7.4$ to -1.2$)$. Pooling of all studies showed similar reductions: systolic $-8.9 \mathrm{~mm} \mathrm{Hg}(-12.5$ to -5.3$)$ and diastolic $-4.0 \mathrm{~mm}$ $\mathrm{Hg}(-5.3$ to -2.7 ; fig 3$)$. 


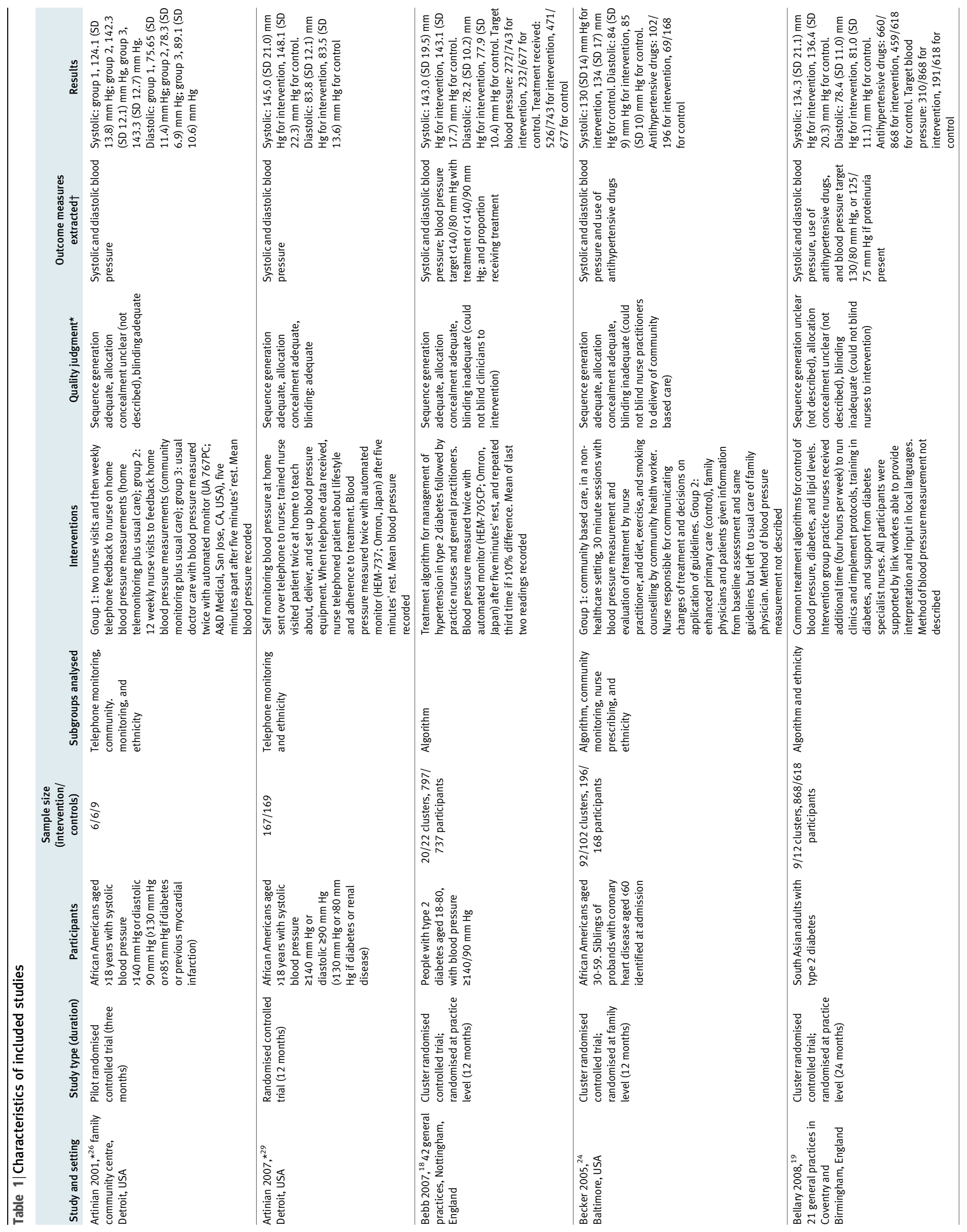




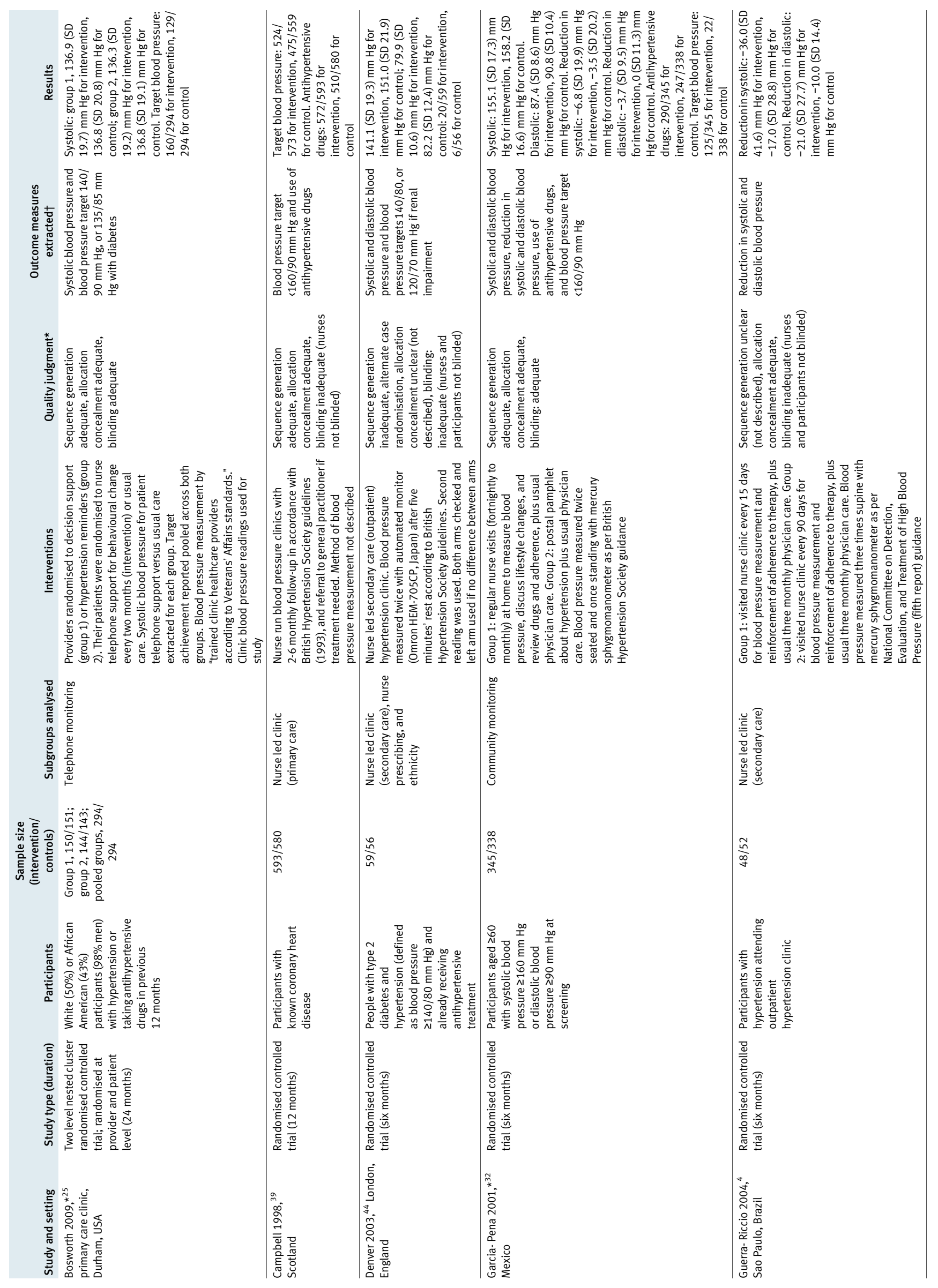




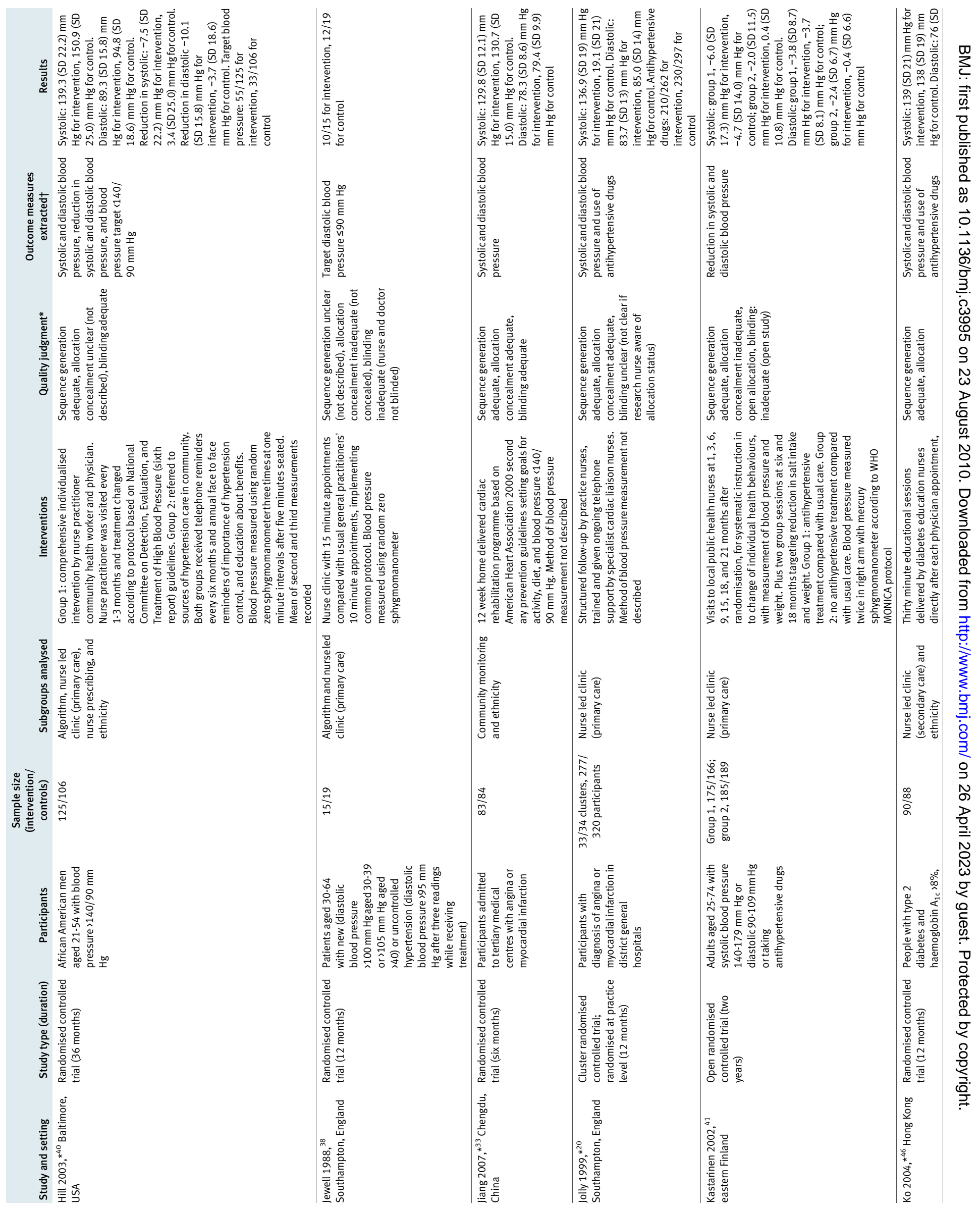




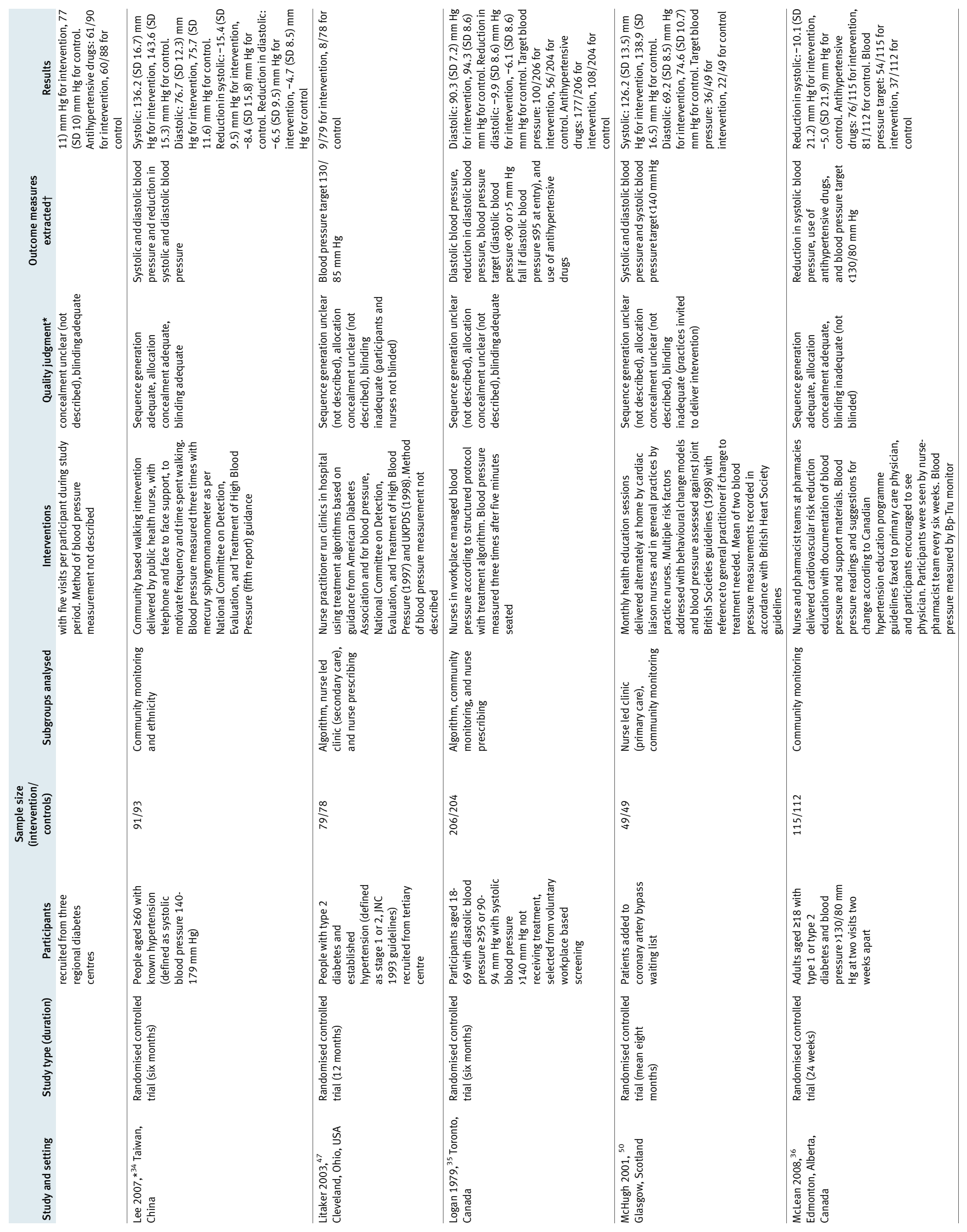

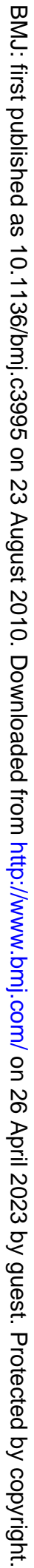




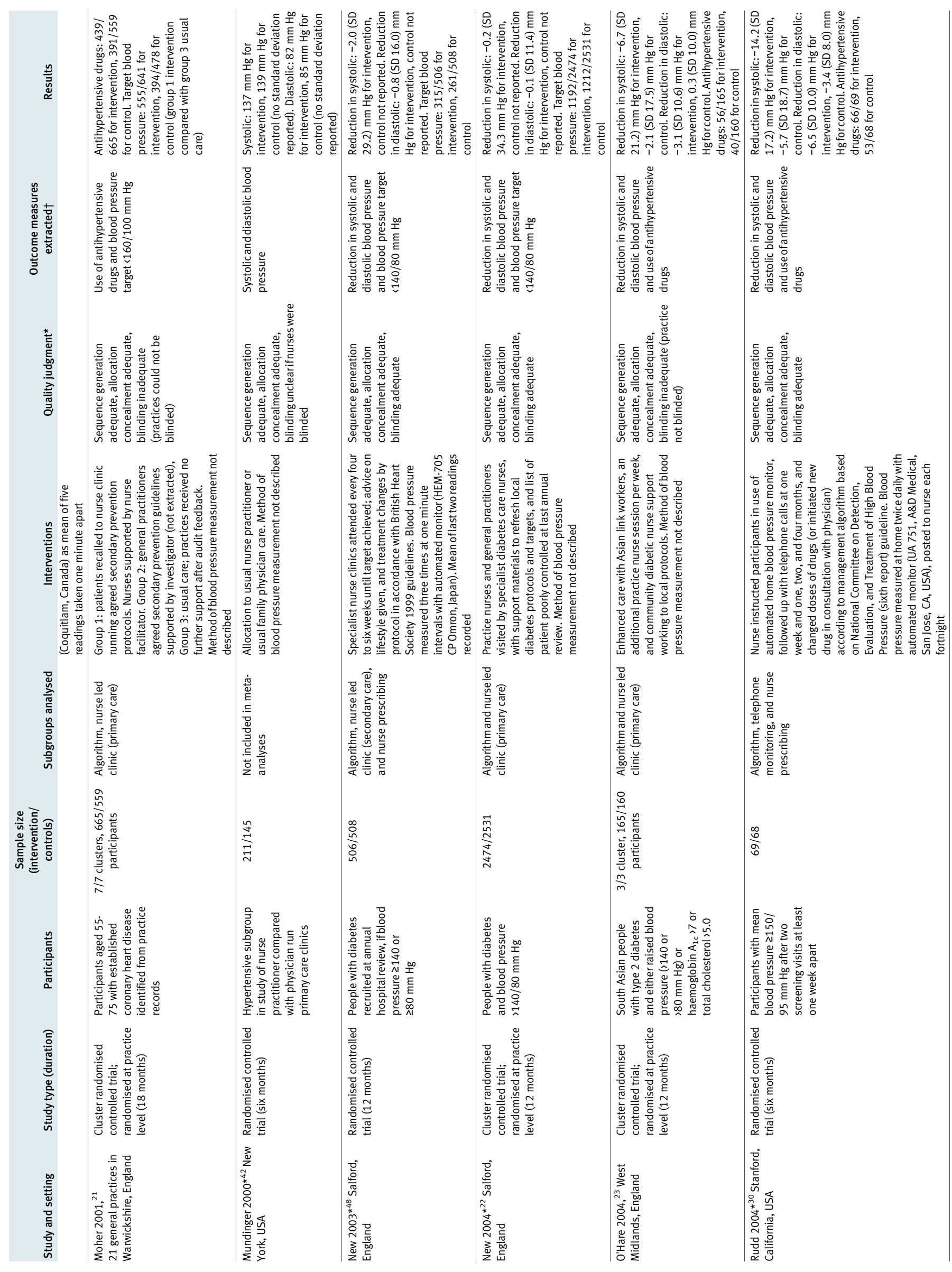

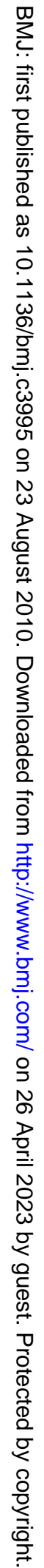




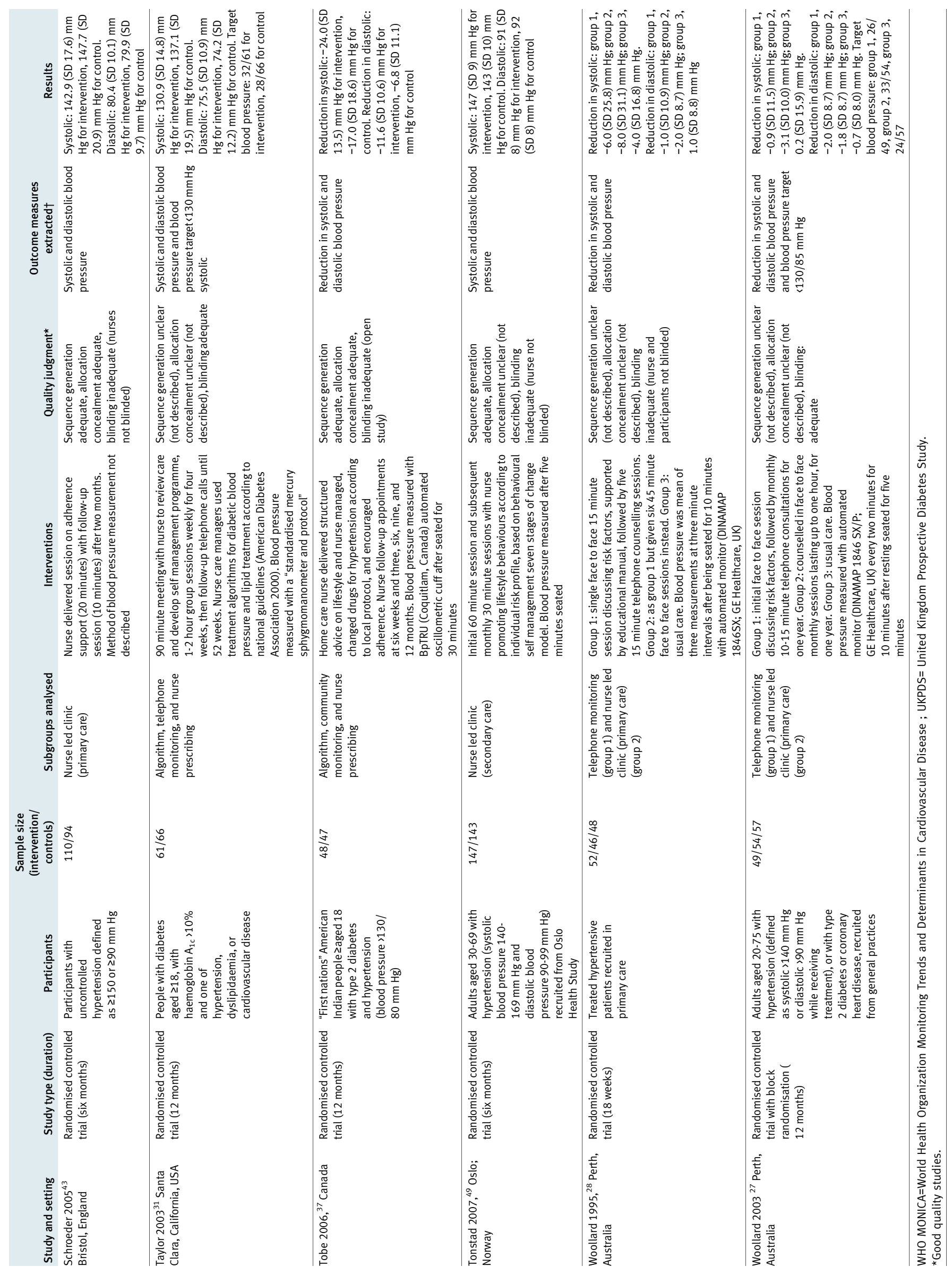


Table 2 |Summary of meta-analyses of studies using nurse led interventions to manage hypertension. Values are for weighted mean differences unless stated otherwise

\begin{tabular}{|c|c|c|c|c|}
\hline \multirow[b]{2}{*}{ Study characteristics } & \multicolumn{2}{|c|}{ Good quality studies } & \multicolumn{2}{|c|}{ All studies } \\
\hline & Mean $(95 \% \mathrm{Cl})$ & Heterogeneity* & Mean $(95 \% \mathrm{Cl})$ & Heterogeneity* \\
\hline \multicolumn{5}{|l|}{ Use of algorithm: } \\
\hline SBP at follow-up & $N R(n=1)$ & NR & $N R(n=5)$ & $P=0.003 ;\left.\right|^{2}=75 \%$ \\
\hline DBP at follow-up & $N R(n=1)$ & NR & $N R(n=6)$ & $P<0.001 ;\left.\right|^{2}=83 \%$ \\
\hline Change in SBP $(\mathrm{mm} \mathrm{Hg})$ from baseline & $-9.7(-14.0$ to -5.4$)(n=2)$ & $P=0.58 ; I^{2}=0 \%$ & $-8.2(-11.5$ to -4.9$)(n=4)$ & $P=0.66 ; I^{2}=0 \%$ \\
\hline Change in DBP $(\mathrm{mm} \mathrm{Hg})$ from baseline & $-4.3(-7.4$ to -1.2$)(n=2)$ & $P=0.23 ; I^{2}=30 \%$ & $\mathrm{NR}(\mathrm{n}=5)$ & $P<0.001 ;\left.\right|^{2}=88 \%$ \\
\hline Achievement of study blood pressure target (relative risk) & $1.09(0.93$ to 1.27$)(n=3)$ & $P=0.12 ; I^{2}=53 \%$ & $N R(n=10)$ & $P=0.006 ; I^{2}=61 \%$ \\
\hline Use of antihypertensive drugs (relative risk) & $N R(n=1)$ & NR & NR $(n=6)$ & $P<0.001 ; I^{2}=91 \%$ \\
\hline \multicolumn{5}{|l|}{ Nurse led clinics in primary care: } \\
\hline SBP at follow-up & $N R(n=2)$ & $P=0.008 ; I^{2}=86 \%$ & $N R(n=4)$ & $P=0.004 ; I^{2}=77 \%$ \\
\hline DBP at follow-up & $-2.9(-6.9$ to 1.1$)(n=2)$ & $P=0.10 ; 1^{2}=63 \%$ & $N R(n=4)$ & $P=0.03 ; I^{2}=66 \%$ \\
\hline Change in SBP from baseline (WMD) & $N R(n=1)$ & NR & $-3.5(-5.9$ to -1.1$)(n=6)$ & $P=0.16 ; I^{2}=36 \%$ \\
\hline Change in DBP from baseline & $N R(n=1)$ & NR & $-1.9(-3.4$ to -0.5$)(n=6)$ & $P=0.12 ; I^{2}=43 \%$ \\
\hline Achievement of study blood pressure target (relative risk) & $1.14(0.83$ to 1.57$)(n=2)$ & $P=0.06 ;\left.\right|^{2}=72 \%$ & $N R(n=7)$ & $P=0.02 ; I^{2}=61 \%$ \\
\hline Use of antihypertensive drugs (relative risk) & $\mathrm{NR}(\mathrm{n}=1)$ & NR & $N R(n=4)$ & $P<0.001 ; I^{2}=90 \%$ \\
\hline \multicolumn{5}{|l|}{ Nurse led clinics in secondary care: } \\
\hline SBP at follow-up & $N R(n=1)$ & NR & $N R(n=3)$ & $P=0.01 ; I^{2}=76 \%$ \\
\hline DBP at follow-up & $N R(n=1)$ & NR & $-1.4(-3.6$ to 0.86$)(n=3)$ & $P=0.88 ;\left.\right|^{2}=0 \%$ \\
\hline Change in SBP from baseline & $N R(n=0)$ & NR & $N R(n=1)$ & NR \\
\hline Change in DBP from baseline & $\mathrm{NR}(\mathrm{n}=0)$ & NR & $N R(n=1)$ & NR \\
\hline Achievement of study blood pressure target (relative risk) & $N R(n=1)$ & NR & $1.47(0.79$ to 2.74$)\{3\}$ & $P=0.06 ; I^{2}=65 \%$ \\
\hline Use of antihypertensive drugs (relative risk) & $N R(n=1)$ & NR & $N R(n=1)$ & NR \\
\hline \multicolumn{5}{|l|}{ Nurse prescribing: } \\
\hline SBP at follow-up & $N R(n=1)$ & NR & $-7.2(-10.9$ to -3.5$)(n=4)$ & $P=0.14 ;\left.\right|^{2}=45 \%$ \\
\hline DBP at follow up & $N R(n=1)$ & NR & $N R(n=5)$ & $P=0.03 ; I^{2}=63 \%$ \\
\hline Change in SBP from baseline & $-9.7(-14.0$ to -5.4$)(n=2)$ & $P=0.58 ; I^{2}=0 \%$ & $-8.9(-12.5$ to -5.3$)(n=3)$ & $P=0.69 ;\left.\right|^{2}=0 \%$ \\
\hline Change in DBP from baseline & $-4.3(-7.4$ to -1.2$)(n=2)$ & $P=0.23 ; l^{2}=30 \%$ & $-4.0(-5.3$ to -2.7$)(n=4)$ & $P=0.66 ;\left.\right|^{2}=0 \%$ \\
\hline Achievement of study blood pressure target (relative risk) & $1.20(0.96$ to 1.50$)(n=2)$ & $P=0.24 ; I^{2}=27 \%$ & $N R(n=6)$ & $P=0.04 ; I^{2}=57 \%$ \\
\hline Use of antihypertensive drugs (relative risk) & $N R(n=1)$ & NR & $N R(n=3)$ & $P=0.01 ; I^{2}=78 \%$ \\
\hline \multicolumn{5}{|l|}{ Telephone monitoring: } \\
\hline SBP at follow-up & $-2.9(-7.5$ to 1.6$)(n=4)$ & $P=0.05 ; I^{2}=62 \%$ & $-3.5(-7.4$ to 0.4$)(n=5)$ & $P=0.05 ; I^{2}=58 \%$ \\
\hline DBP at follow-up & $\mathrm{NR}(\mathrm{n}=2)$ & $P=0.02 ;\left.\right|^{2}=81 \%$ & $-1.1(-5.8$ to 3.6$)(n=3)$ & $P=0.06 ; 1^{2}=65 \%$ \\
\hline Change in SBP from baseline & $N R(n=1)$ & NR & $-3.9(-8.9$ to 1.0$)(n=3)$ & $P=0.17 ; I^{2}=44 \%$ \\
\hline Change in DBP from baseline & $N R(n=1)$ & NR & $-2.1(-4.1$ to -0.3$)(n=3)$ & $P=0.72 ;\left.\right|^{2}=0 \%$ \\
\hline Achievement of study blood pressure target (relative risk) & $N R(n=1)$ & NR & $1.24(1.08$ to 1.43$)(n=3)$ & $P=1.00 ;\left.\right|^{2}=0 \%$ \\
\hline Use of antihypertensive drugs (relative risk) & $N R(n=1)$ & NR & $\mathrm{NR}(\mathrm{n}=1)$ & NR \\
\hline \multicolumn{5}{|l|}{ Community monitoring: } \\
\hline SBP at follow-up & $-3.4(-6.1$ to -0.7$)(n=4)$ & $P=0.21 ;\left.\right|^{2}=33 \%$ & $N R(n=6)$ & $P=0.03 ; 1^{2}=60 \%$ \\
\hline DBP at follow-up & $N R(n=4)$ & $P=0.02 ; I^{2}=69 \%$ & $N R(n=7)$ & $P=0.01 ; I^{2}=64 \%$ \\
\hline Change in SBP from baseline & $-4.8(-8.3$ to -1.2$)(n=2)$ & $P=0.18 ;\left.\right|^{2}=44 \%$ & $-4.8(-7.0$ to -2.7$)(n=4)$ & $P=0.51 ;\left.\right|^{2}=0 \%$ \\
\hline Change in DBP from baseline & $-3.1(-4.8$ to -1.3$)(n=2)$ & $P=0.22 ; I^{2}=33 \%$ & $-3.5(-4.5$ to -2.5$)(n=4)$ & $\mathrm{P}=0.54 ; 1^{2}=0 \%$ \\
\hline Achievement of study blood pressure target (relative risk) & $\mathrm{NR}(\mathrm{n}=1)$ & NR & $N R(n=4)$ & $P<0.001 ;\left.\right|^{2}=90 \%$ \\
\hline Use of antihypertensive drugs (relative risk) & $N R(n=1)$ & NR & $N R(n=4)$ & $P<0.001 ;\left.\right|^{2}=90 \%$ \\
\hline \multicolumn{5}{|l|}{ Ethnic minority analyses } \\
\hline \multicolumn{5}{|l|}{ SBP at follow-up: } \\
\hline African American & $-7.8(-14.6$ to -0.9$)(n=4)$ & $P=0.05 ; I^{2}=63 \%$ & $-6.3(-10.7$ to $-1.9(n=5)$ & $P=0.06 ; I^{2}=56 \%$ \\
\hline Chinese & $-2.6(-7.5$ to 2.3$)(n=3)$ & $P=0.04 ; I^{2}=68 \%$ & $-2.6(-7.5$ to 2.3$)(n=3)$ & $P=0.04 ; I^{2}=68 \%$ \\
\hline Pooled minority groups & $N R(n=7)$ & $P=0.009 ; 1^{2}=65 \%$ & $N R(n=10)$ & $P=0.009 ; I^{2}=59 \%$ \\
\hline \multicolumn{5}{|l|}{ DBP at follow-up: } \\
\hline African American & NR $(n=4)$ & $P=0.02 ; I^{2}=71 \%$ & $N R(n=5)$ & $P=0.03 ; I^{2}=62 \%$ \\
\hline Chinese & $-0.5(-2.3$ to 1.3$)(n=3)$ & $P=0.61 ; I^{2}=0 \%$ & $-0.5(-2.3$ to 1.3$)(n=3)$ & $P=0.61 ;\left.\right|^{2}=0 \%$ \\
\hline Pooled minority groups & $-1.7(-3.9$ to 0.6$)(n=7)$ & $P=0.06 ;\left.\right|^{2}=51 \%$ & $-1.7(-3.0$ to -0.4$)(n=10)$ & $P=0.07 ; 1^{2}=43 \%$ \\
\hline \multicolumn{5}{|l|}{ Change in SBP from baseline: } \\
\hline African American & $N R(n=1)$ & NR & $N R(n=1)$ & NR \\
\hline Chinese & $N R(n=1)$ & NR & $N R(n=1)$ & NR \\
\hline
\end{tabular}




\begin{tabular}{|c|c|c|c|c|}
\hline \multirow[b]{2}{*}{ Study characteristics } & \multicolumn{2}{|c|}{ Good quality studies } & \multicolumn{2}{|c|}{ All studies } \\
\hline & Mean $(95 \% \mathrm{Cl})$ & Heterogeneity* & Mean $(95 \% \mathrm{Cl})$ & Heterogeneity* \\
\hline Mixed non-white & $N R(n=0)$ & NR & $-17.1(-29.5$ to -4.8$)(n=2)$ & $P=0.59 ;\left.\right|^{2}=0 \%$ \\
\hline Pooled minority groups & $-8.4(-12.0$ to -4.7$)(n=2)$ & $P=0.32 ; I^{2}=1 \%$ & $-8.1(-11.0$ to -5.2$)(n=6)$ & $P=0.53 ;\left.\right|^{2}=0 \%$ \\
\hline \multicolumn{5}{|c|}{ Change in DBP from baseline: } \\
\hline African American & $N R(n=1)$ & NR & $N R(n=1)$ & NR \\
\hline Chinese & $N R(n=1)$ & NR & $N R(n=1)$ & NR \\
\hline Mixed non-white & $N R(n=0)$ & NR & $-7.9(-16.3$ to 0.6$)(n=2)$ & $P=0.26 ; I^{2}=21 \%$ \\
\hline Pooled minority groups & $-3.7(-8.2$ to 0.7$)(n=2)$ & $P=0.08 ;\left.\right|^{2}=67 \%$ & $-4.1(-6.4$ to -1.8$)(n=6)$ & $P=0.27 ; I^{2}=22 \%$ \\
\hline \multicolumn{5}{|c|}{ Achievement of study blood pressure target (relative risk): } \\
\hline Pooled minority groups & $N R(n=1)$ & NR & $N R(n=3)$ & $P=0.04 ; I^{2}=68 \%$ \\
\hline \multicolumn{5}{|c|}{ Use of antihypertensive drugs (relative risk) } \\
\hline South Asian & $N R(n=0)$ & NR & $1.22(0.90$ to 1.65$)(n=2)$ & $P=0.22 ; I^{2}=34 \%$ \\
\hline Pooled minority groups & $N R(n=1)$ & NR & $1.22(1.02$ to 1.47$)(n=4)$ & $P=0.33 ; I^{2}=12 \%$ \\
\hline
\end{tabular}

Only one good quality study reported absolute blood pressure as an outcome, but pooling of four studies showed a significantly lower absolute outcome systolic blood pressure in favour of nurse prescribing: weighted mean difference $-7.2 \mathrm{~mm} \mathrm{Hg}(95 \%$ confidence interval -10.9 to -3.5$).^{30313740}$

Two good quality studies showed no difference in achievement of study blood pressure target (relative risk $1.20,95 \%$ confidence interval 0.96 to 1.50$) \cdot{ }^{40}{ }^{48} \mathrm{Sig}$ nificant statistical and clinical heterogeneity precluded further pooled analysis.

\section{Telephone monitoring}

Seven studies included telephone monitoring of blood pressure by nurses. ${ }^{25-31}$ Meta-analysis of four groups from three good quality studies showed no significant difference in outcome systolic blood pressure (weighted mean difference $-2.9 \mathrm{~mm} \mathrm{Hg}, 95 \%$ confidence interval -7.5 to 1.6$).{ }^{252629}$ Pooling of all studies gave a similar result $(-3.5 \mathrm{~mm} \mathrm{Hg},-7.4$ to 0.4 ; fig 4$)$, and pooling of three studies also showed no difference for outcome diastolic blood pressure $(-1.1 \mathrm{~mm} \mathrm{Hg}$, -5.8 to 3.6$).{ }^{262931}$

Pooled data from three studies ${ }^{252731}$ (one of good quality $^{25}$ ) showed a higher achievement of study blood pressure targets with telephone monitoring than with usual care (relative risk 1.24, 95\% confidence interval 1.08 to 1.43$)$.

\section{Community monitoring}

Eight studies involved nurse interventions delivered outside of healthcare settings. Locations included the home ${ }^{32333750}$ community centres, ${ }^{2426}$ or a choice of both. ${ }^{34}$ One study was set in the workplace ${ }^{35}$ and one in a pharmacy. ${ }^{36}$ Pooled data from four good quality studies $^{2632-34}$ showed a lower outcome systolic blood pressure in favour of monitoring in the community (weighted mean difference $-3.4 \mathrm{~mm} \mathrm{Hg}, 95 \%$ confidence interval -6.1 to -0.7 ; fig 5 ) and two good quality studies showed greater magnitudes of blood pressure reduction with community monitoring than with usual care: systolic $-4.7 \mathrm{~mm} \mathrm{Hg}(-8.3$ to -1.2$)$ and diastolic $-3.1 \mathrm{~mm} \mathrm{Hg}(-4.8$ to -1.3$) .{ }^{32}{ }^{34}$ Pooling of data from all four studies also showed a greater magnitude of reductions in favour of the intervention: systolic $-4.8 \mathrm{~mm} \mathrm{Hg}$ $(-7.0 \text { to }-2.7)^{32343637}$ and diastolic $-3.5 \mathrm{~mm} \mathrm{Hg}(-4.5$ to $-2.5){ }^{32} 343537$

Four studies, ${ }^{32353650}$ including one of good quality, ${ }^{32}$ reported significantly better achievement of blood pressure targets in favour of the intervention, but significant heterogeneity precluded pooled analysis.

\section{Nurse led clinics}

Fourteen studies were of nurse led clinics in primary care $^{20-2327283538-4350}$ and six in secondary care settings. ${ }^{44-49}$ For primary care studies, two of good quality showed no difference in diastolic blood pressure

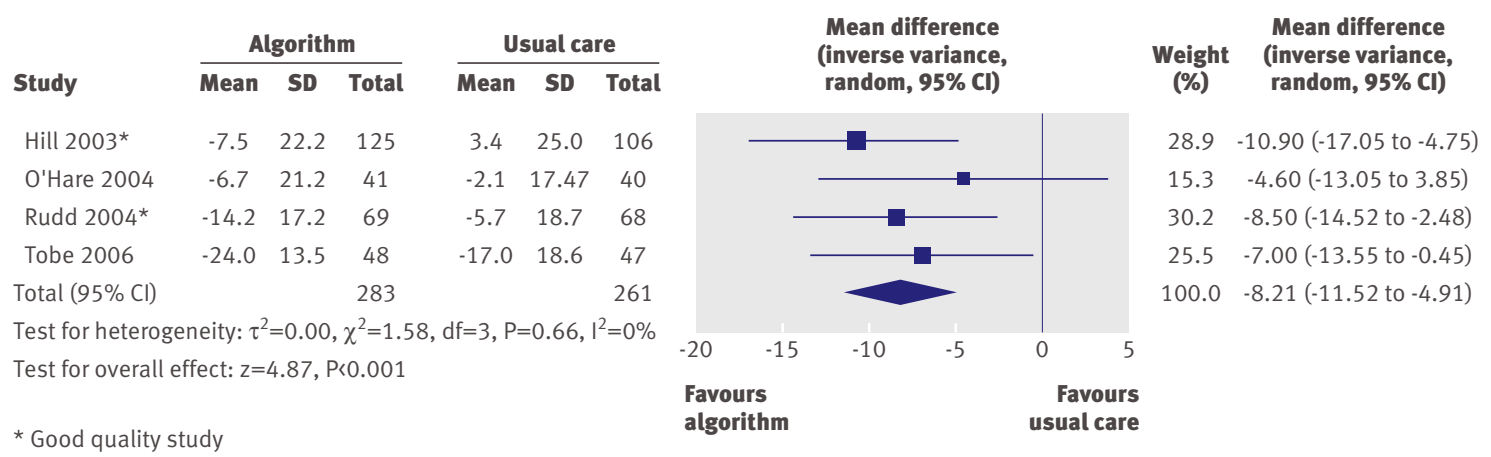

Fig 2 | Change in systolic blood pressure with nurse led use of algorithm compared with usual care 


\begin{tabular}{|c|c|c|c|c|c|c|c|c|c|c|c|c|c|}
\hline \multirow[b]{2}{*}{ Study } & \multicolumn{3}{|c|}{ Nurse prescribing } & \multicolumn{3}{|c|}{ Usual care } & & \multirow{2}{*}{\multicolumn{3}{|c|}{$\begin{array}{c}\text { Mean difference } \\
\text { (inverse variance, } \\
\text { random, } 95 \% \mathrm{Cl} \text { ) }\end{array}$}} & & \multirow{2}{*}{$\begin{array}{l}\text { Weight } \\
\text { (\%) }\end{array}$} & \multirow{2}{*}{$\begin{array}{l}\text { Mean difference } \\
\text { (inverse variance, } \\
\text { random, } 95 \% \mathrm{Cl} \text { ) }\end{array}$} \\
\hline & Mean & SD & Total & Mean & SD & Total & & & & & & & \\
\hline \multicolumn{14}{|c|}{ Change in systolic blood pressure } \\
\hline Hill 2003* & -7.5 & 22.2 & 125 & 3.4 & 25.0 & 106 & & & & & & 34.2 & $-10.90(-17.05$ to -4.75$)$ \\
\hline Rudd 2004* & -14.2 & 17.2 & 69 & -5.7 & 18.7 & 68 & & & & & & 35.7 & $-8.50(-14.52$ to -2.48$)$ \\
\hline Tobe 2006 & -24.0 & 13.5 & 48 & -17.0 & 18.6 & 47 & & & & & & 30.1 & $-7.00(-13.55$ to -0.45$)$ \\
\hline Total $(95 \% \mathrm{Cl})$ & & & 242 & & & 221 & & & & & & 100.0 & $-8.87(-12.46,-5.27)$ \\
\hline \multirow{2}{*}{\multicolumn{14}{|c|}{$\begin{array}{l}\text { Test for heterogeneity: } \tau^{2}=0.00, \chi^{2}=0.75, d f=2, P=0.69, I^{2}=0 \% \\
\text { Test for overall effect: } z=4.84, P<0.001\end{array}$}} \\
\hline & & & & & & & & & & & & & \\
\hline \multicolumn{14}{|c|}{ Change in diastolic blood pressure } \\
\hline Hill 2003* & -10.1 & 15.8 & 125 & -3.7 & 18.6 & 106 & & & & & & 8.7 & $-6.40(-10.90$ to -1.90$)$ \\
\hline Logan 1979 & -9.9 & 8.6 & 206 & -6.1 & 8.6 & 204 & & & & & & 63.1 & $-3.80(-5.46$ to -2.14$)$ \\
\hline Rudd 2004* & -6.5 & 10.0 & 69 & -3.4 & 8.0 & 68 & & & & & & 19.1 & $-3.10(-6.13$ to -0.07$)$ \\
\hline Tobe 2006 & -11.6 & 10.6 & 48 & -6.8 & 11.1 & 47 & & & & $\Rightarrow$ & & 9.2 & $-4.80(-9.17$ to -0.43$)$ \\
\hline Total $(95 \% \mathrm{Cl})$ & & & 448 & & & 425 & & & & & & 100.0 & $-3.98(-5.31$ to -2.66$)$ \\
\hline \multicolumn{7}{|c|}{ Test for heterogeneity: $\tau^{2}=0.00, \chi^{2}=1.62, d f=3, P=0.66, I^{2}=0 \%$} & -20 & -15 & -10 & -5 & 0 & & \\
\hline \multicolumn{7}{|c|}{ Test for overall effect: $z=5.90, P<0.001$} & & $\begin{array}{l}\text { rs } \\
\text { presc }\end{array}$ & & & $\begin{array}{r}\text { Favours } \\
\text { usual care }\end{array}$ & & \\
\hline
\end{tabular}

Fig 3 Changes in blood pressure with interventions including nurse prescribing compared with usual care

$(-2.9 \mathrm{~mm} \mathrm{Hg},-6.9$ to 1.1$) .{ }^{2040}$ Pooling of all studies showed a greater magnitude of reduction in blood pressure for nurse led clinics compared with usual care (systolic $-3.5 \mathrm{~mm} \mathrm{Hg},-5.9$ to -1.1 and diastolic $-1.9 \mathrm{~mm}$ $\mathrm{Hg},-3.4$ to -0.5 ; fig 6$),{ }^{2327284041}$ and two good quality studies showed no difference in achievement of blood pressure targets with nurse led clinics (relative risk 1.14, $95 \%$ confidence interval 0.83 to 1.57$).{ }^{2240}$

For secondary care clinics, only two were of good quality and did not report comparable outcomes. ${ }^{4648}$ For all studies, pooling of data from three studies showed no difference in outcome diastolic blood pressure (weighted mean difference $-1.4 \mathrm{~mm} \mathrm{Hg},-3.6$ to $0.86)^{444649}$ and no greater achievement of study blood pressure targets (relative risk 1.47, 95\% confidence interval 0.79 to 2.74$)^{44478}$ in nurse led clinics compared with usual care.

\section{Ethnicity}

Significantly lower systolic blood pressure was achieved for any nurse led intervention for four groups from three good quality studies recruiting African American participants (weighted mean difference $-7.8 \mathrm{~mm} \mathrm{Hg}, 95 \%$ confidence interval -14.6 to -0.9$)^{242940}$ but neither systolic nor diastolic blood pressure was lower on pooling of three good quality studies of Chinese participants (systolic $-2.6 \mathrm{~mm} \mathrm{Hg},-7.5$ to 2.3 and diastolic $-0.5 \mathrm{~mm} \mathrm{Hg},-2.3$ to 1.3 ; fig 7). ${ }^{33446}$ Pooling of two studies, neither of good quality, showed no significant increase in the use of antihypertensive drugs in South Asian participants (relative risk 1.22, 95\% confidence interval 0.90 to 1.65$),{ }^{1923}$ but pooling of four studies across different ethnic groupings did show a small increase in favour of any nurse led intervention compared with usual care $(1.22,1.02$ to 1.47$) .{ }^{19232444}$

\section{Cost and cost effectiveness}

Only four studies presented any data. From the United Kingdom one study reported a cost per patient of $£ 434$ $(€ 525, \$ 632)$ over two years to provide additional nurse clinics and support from specialist nurses, representing $£ 28933$ per quality adjusted life year gained ${ }^{19}$

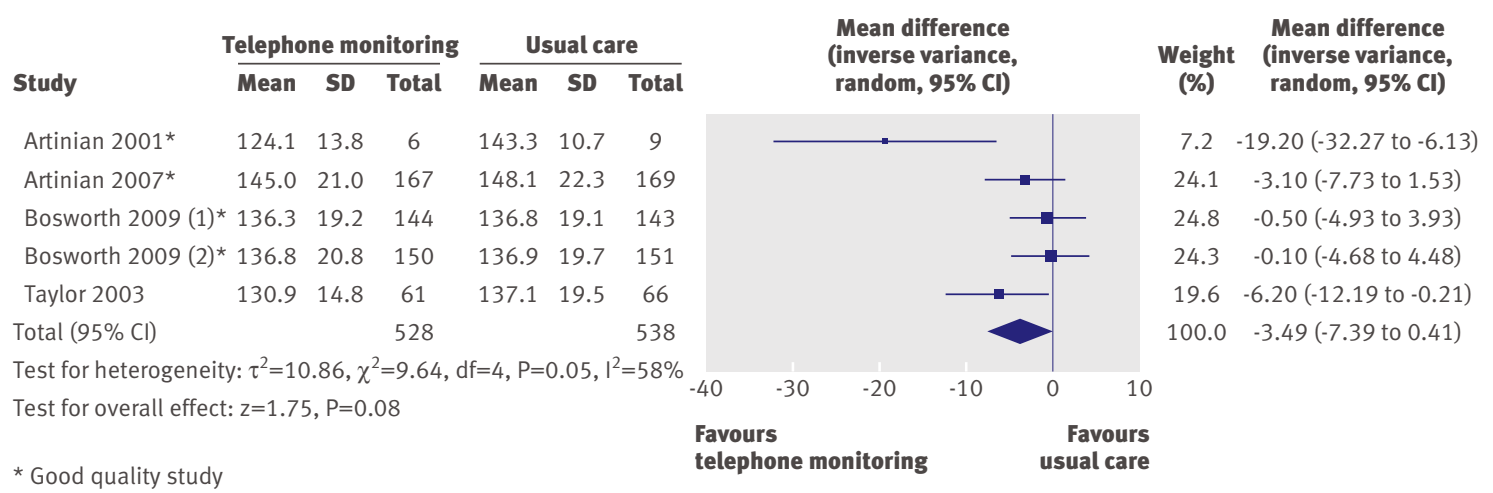

Fig 4 | Absolute systolic blood pressure after nurse led telephone monitoring compared with usual care 


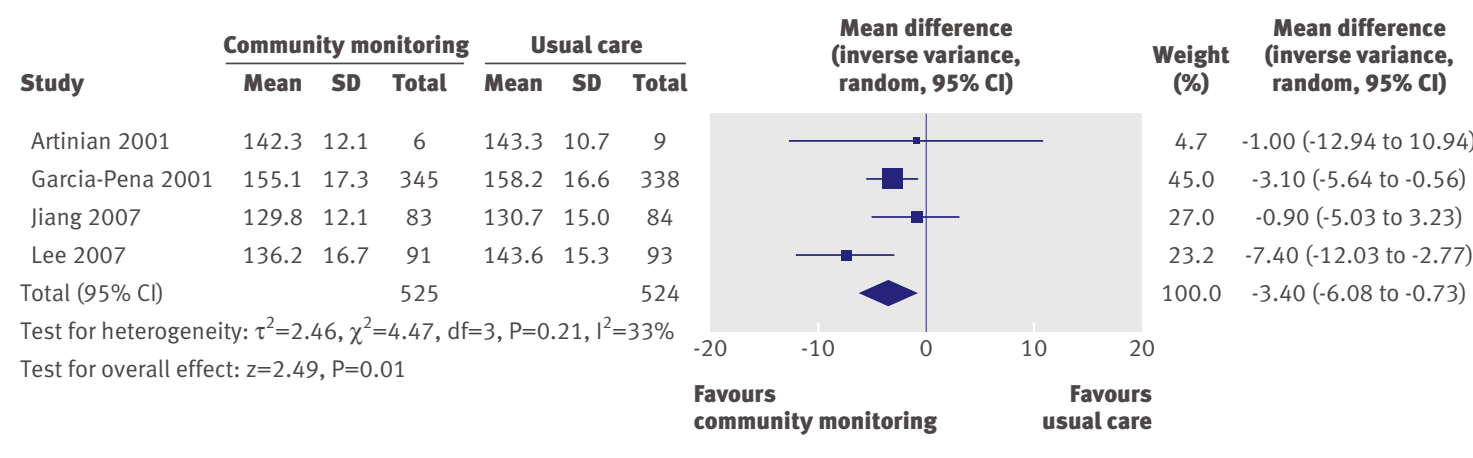

Fig 5 | Absolute systolic blood pressure after community nurse led interventions compared with usual care for good quality studies and another study found that primary care costs were $£ 9.50$ per patient compared with $£ 5.08$ for usual care. ${ }^{43}$ In the United States a study reported a $50 \%$ higher total cost of staff at $\$ 134.68(£ 92.65, € 111.90)$ per patient treated in a nurse led clinic compared with $\$ 93.70$ for usual care, ${ }^{47}$ but a Mexican study reported $\$ 4(£ 2.75$, $€ 3.32$ ) per patient or $\$ 1$ per $1 \mathrm{~mm} \mathrm{Hg}$ reduction of systolic blood pressure. ${ }^{32}$

\section{DISCUSSION}

In comparison with usual patterns of care, nurse led interventions that included a stepped treatment algorithm showed significantly greater reductions of systolic and diastolic blood pressure, but this was not associated with higher achievement of blood pressure targets. Studies incorporating nurse led prescribing also showed bigger reductions of systolic and diastolic blood pressure. Telephone monitoring was associated with higher achievement of study targets for blood pressure. Community monitoring showed lower outcome systolic blood pressure, greater reductions in systolic and diastolic blood pressure, and, although pooling of data was not possible, greater achievement of study blood pressure targets. Nurse led clinics in primary care achieved greater reductions in systolic and diastolic blood pressure compared with usual care. No clear beneficial effects on our primary outcomes were observed from secondary care clinics.

Pooled interventions showed significantly lower systolic blood pressure in African American participants with nurse led interventions than with usual care, but little difference for other ethnic minority groups.

\begin{tabular}{|c|c|c|c|c|c|c|}
\hline \multirow[b]{2}{*}{ Study } & \multicolumn{3}{|c|}{ Nurse led care } & \multicolumn{3}{|c|}{ Usual care } \\
\hline & Mean & SD & Total & Mean & SD & Total \\
\hline \multicolumn{7}{|c|}{ Change in systolic blood pressure } \\
\hline Hill 2003* & -7.5 & 22.2 & 125 & 3.4 & 25.0 & 106 \\
\hline Kastarinen 2002 (treatment) & -6.0 & 17.3 & 185 & -4.7 & 14.0 & 189 \\
\hline Kastarinen 2002 (no treatment) & -2.0 & 11.5 & 175 & 0.4 & 10.8 & 166 \\
\hline O'Hare 2004 & -6.7 & 21.2 & 41 & -2.1 & 17.47 & 40 \\
\hline Woollard 1995 & -8.0 & 31.1 & 46 & -4.0 & 16.8 & 48 \\
\hline Woollard 2003 & -3.1 & 10.0 & 54 & 0.2 & 15.9 & 57 \\
\hline Total $(95 \% \mathrm{Cl})$ & & & 626 & & & 606 \\
\hline \multicolumn{7}{|c|}{ Test for heterogeneity: $\tau^{2}=3.00, \chi^{2}=7.86, d f=5, P=0.16, I^{2}=36 \%$} \\
\hline \multicolumn{7}{|c|}{ Test for overall effect: $z=2.84, P=0.005$} \\
\hline
\end{tabular}

Change in diastolic blood pressure

$\begin{array}{lcccccc}\text { Hill 2003* } & -10.1 & 15.8 & 125 & -3.7 & 18.6 & 106 \\ \text { Kastarinen 2002 (no treatment) } & -2.4 & 6.7 & 175 & -0.4 & 6.6 & 166 \\ \text { Kastarinen 2002 (treatment) } & -3.8 & 8.7 & 185 & -3.7 & 8.1 & 189 \\ \text { O'Hare 2004 } & -3.1 & 10.6 & 22 & 0.3 & 10.0 & 22 \\ \text { Woollard 1995 } & -2.0 & 8.7 & 46 & 1.0 & 8.8 & 48 \\ \text { Woollard 2003 } & -1.8 & 8.7 & 54 & -0.7 & 8.0 & 57 \\ \text { Total (95\% Cl) } & & 607 & & & 588 \\ \text { Test for heterogeneity: } \tau^{2}=1.28, \chi^{2}=8.70, \mathrm{df}=5, \mathrm{P}=0.12, \mathrm{I}^{2}=43 \%\end{array}$

Test for overall effect: $z=2.55, P=0.01$

* Good quality study

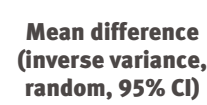

(inverse variance,
random, $95 \% \mathrm{Cl}$ )

106
89
0
8
7
76

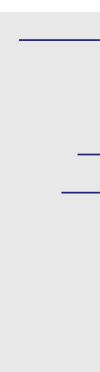

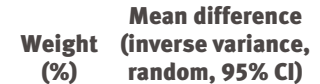

Weight (inverse variance,

(\%)

$11.7-10.90(-17.05$ to -4.75$)$

$26.5-1.30(-4.49$ to 1.89$)$

$33.6-2.40(-4.77$ to -0.03$)$

$7.0-4.60(-13.05$ to 3.85$)$

$5.0-4.00(-14.17$ to 6.17$)$

$16.2-3.30(-8.21$ to 1.61$)$

$100.0-3.48(-5.88$ to -1.08$)$
Fig 6 Changes in blood pressure with primary care nurse led clinics compared with usual care 


\section{Strengths and limitations of this review}

Since blood pressure was reported variously as final blood pressure or change from baseline for systolic or diastolic readings, less pooling of results was possible than may have been anticipated.

Thirteen of the 33 included randomised controlled trials met our quality criteria. Only three of these were from the United Kingdom ${ }^{202248}$ and none investigated an unselected primary care hypertensive population. Therefore the evidence base for nurse led care of hypertension in the United Kingdom relies on generalisation of findings from other, principally American, healthcare systems. In total, 12 trials were identified from the United Kingdom, of which six studied blood pressure control in people with diabetes ${ }^{181922234448}$, four in patients with ischaemic heart disease, ${ }^{20213950}$ and two in people with uncontrolled hypertension. ${ }^{3843}$

We restricted our search to articles in English, which may have excluded some potential international data; however, we consider it unlikely that significant evidence applicable to UK health care would have only been published in another language.
The usual reason for judging a trial's quality as inadequate was weakness of blinding. As it was not possible for the participants to always be blinded to whether they were seeing a doctor, nurse, or other health professional, this limitation must be accepted for any face to face intervention. We aimed to assess blinding of the researchers collecting outcome data to the intervention; these were often the same nurses who delivered the intervention and therefore were open to bias. This lack of formal blinding in trials is recognised as a methodological challenge ${ }^{51}$ but need not be seen as a limitation because implementation of these findings would also necessarily be unblinded, so a pragmatic approach to studying these interventions can be relevant. ${ }^{52}$ Future trials will, however, need carefu design to minimise bias.

One third of studies gave no description of the method used to measure blood pressure and only seven referred to published guidelines on blood pressure measurement, therefore the reliability of reported outcome measures cannot be judged easily.

Although interventions such as use of algorithms and nurse prescribing were associated with meaningful

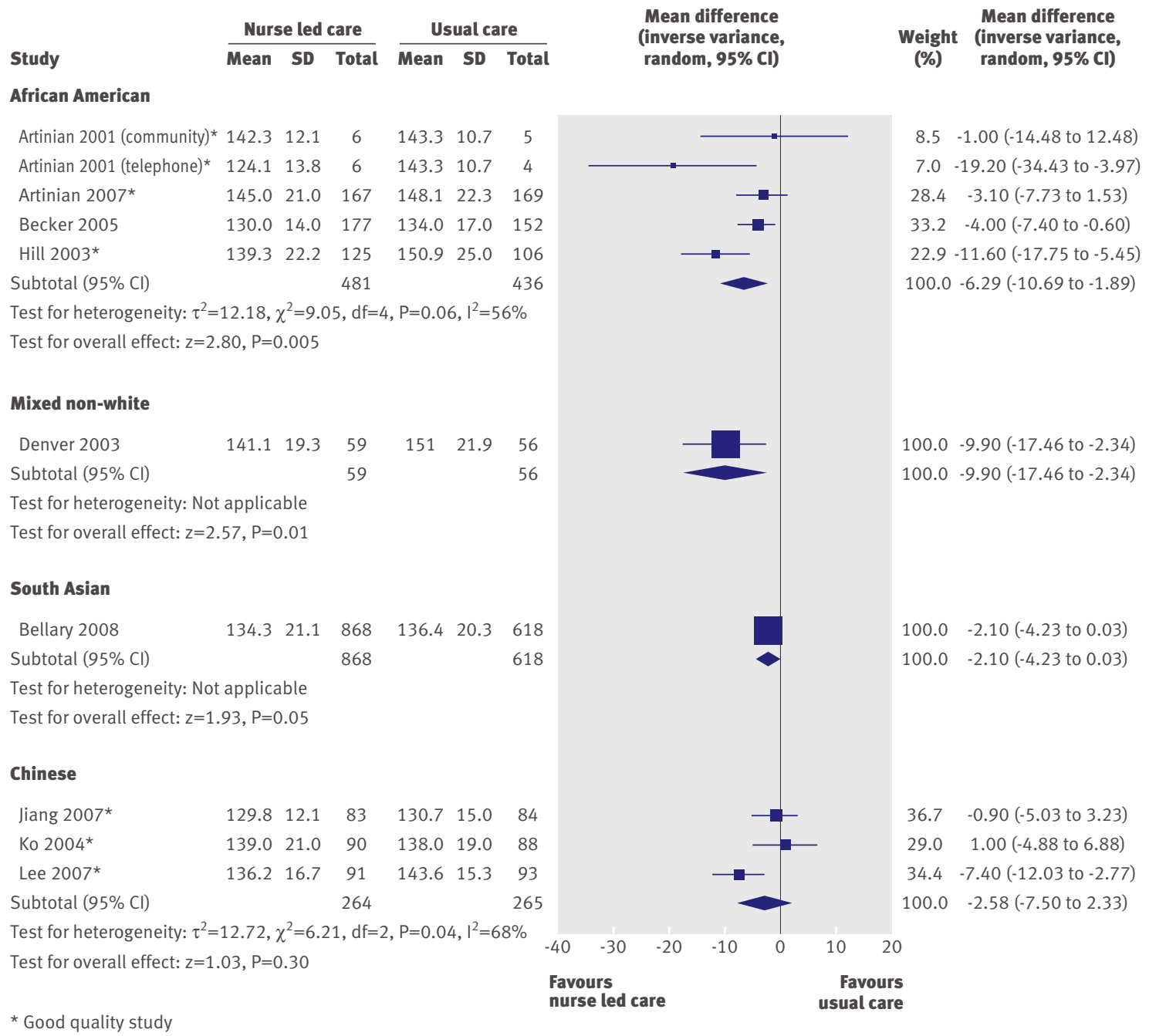


blood pressure reductions there was not a concomitant rise in achievement of target blood pressure. Although apparently inconsistent this could be a sample size effect, with some studies underpowered to show differences in dichotomous outcomes. It may also be explained by the noticeable variation in individual blood pressure targets in the studies, which were sometimes composite or multiple. ${ }^{18} 193544$ Therefore reporting of absolute blood pressure reductions may be the more robust outcome measure for comparison in future reviews.

Many studies combined the use of a treatment algorithm with the nurse intervention; therefore the results contributed to both analyses. It was not possible within this review to separate out thoroughly the components of each intervention that were or were not effective.

For most studies the duration of follow-up was relatively short; only five followed participants for more than 12 months. ${ }^{1921254041}$ Therefore it is not possible to extrapolate the findings as sustained benefits of the interventions.

We present evidence of benefit in some studies of ethnic minority groups because hypertension is recognised to carry higher levels of morbidity and mortality in some such populations. ${ }^{8}$ These findings, however, pool different types of intervention so cannot identify specific nurse led interventions of benefit in these groups. Furthermore, the "usual care" arm of some studies, predominantly from America, ${ }^{24262940}$ represented minimal care; therefore the benefits shown may be larger than could be expected if introduced to more inclusive healthcare systems, such as are found in the United Kingdom.

We included cost and cost effectiveness as a secondary outcome measure. It is, however, possible that other papers discussing this outcome (that is, non-randomised controlled trials) were not retrieved by our search strategy. Therefore a more thorough primary review of cost data may be needed.

\section{Comparison with existing literature}

The traditional view of the nurse's role in hypertension care is to educate, advise, measure blood pressure, ${ }^{51}$ and enhance self management. ${ }^{53}$ Previous reviews have suggested that nurse led care may achieve better outcomes by increased adherence to protocols and guidelines, but we found insufficient evidence to confirm this. ${ }^{14}$ The most recent review ${ }^{12}$ identified an organised system of regular review and stepped care as essential components of successful interventions. This updated review supports this view, showing benefits in blood pressure reduction with the use of a treatment algorithm. No previous review has found sufficient evidence to support the assertion that nurse prescribing should be a key component of nurse interventions for hypertension ${ }^{14}$; however, this review has shown better blood pressure outcomes in favour of nurse prescribing based on studies in American healthcare systems.

Interventions varied greatly in intensity and presumably therefore in cost. Lack of information on cost effectiveness has been identified previously, ${ }^{54}$ and although this was only a secondary outcome measure for this review we noted that only four studies, including one of good quality, ${ }^{32}$ reported on costs. ${ }^{19324347}$ All four showed higher costs for the intervention, approaching $50 \%$ higher in two cases. ${ }^{434}$ Only one study seemed to be cost effective, ${ }^{32}$ but costs depend on the healthcare system within which the intervention is delivered, so we were unable to show any cost benefit that could be generalised across differing systems. Although nurses may save on salary costs, the evidence is conflicting, with potential savings being offset by an increased length of consultation. ${ }^{55}$ Evidence of cost benefit in acute self limiting conditions ${ }^{56}$ cannot be assumed to translate to the management of chronic disease, so future trials should incorporate a formal cost effectiveness analysis within their design.

Hypertension is identified with higher prevalence and morbidity levels in some ethnic minority groups such as African Americans and South Asians ${ }^{57}$ Studies recruiting from these populations found significant reductions in blood pressures with any nurse led intervention. For studies from non-UK healthcare systems, "usual care" represented minimal or absent care. ${ }^{2940}$ We therefore interpret this with caution.

\section{Implications for clinical practice}

The delivery of nurse led care in chronic conditions is a complex intervention. This review suggests that such care can improve on doctor led or usual care of hypertension. The key component of an intervention seems to be a structured treatment algorithm, and we have found evidence in favour of nurse prescribing. Although no clear benefits were seen for secondary care clinics improvements were found in both primary care and community based settings, suggesting that these findings can be applied to primary care clinics in the United Kingdom, or equivalent community settings in other healthcare systems. Although the absolute differences in blood pressure seem small-for example, a $4 \mathrm{~mm} \mathrm{Hg}$ greater reduction in diastolic blood pressure with nurse prescribing than with usual care, a $2 \mathrm{~mm} \mathrm{Hg}$ reduction in diastolic blood pressure is associated with a 15\% reduction in risk of stroke or transient ischaemic attack in primary prevention. ${ }^{58}$ Similarly a $20-30 \%$ reduction in frequency of stroke, coronary heart disease, major cardiovascular events, and cardiovascular death is seen with a $3 \mathrm{~mm} \mathrm{Hg}$ reduction in systolic blood pressure ${ }^{59}$ and differences of this magnitude or greater are seen with nurse led clinics, nurse prescribing, and the use of an algorithm.

\section{Implications for future research}

In this review we found international evidence of benefit from nurse led interventions but no evidence of good quality was derived from an unselected UK population with hypertension in primary care. Evidence from other healthcare systems cannot necessarily be generalised, therefore further studies relevant to the United Kingdom are needed. Such studies should ideally include a structured algorithm, examine the role of nurse led prescribing, and include a robust 


\section{WHAT IS ALREADY KNOWN ON THIS TOPIC}

Nurses are integral members of the primary healthcare team and are involved in the management of hypertension

Previous literature reviews have suggested that nurse led care may be beneficial in the care of hypertension but the data are conflicting

\section{WHAT THIS STUDY ADDS}

This review presents evidence to support structured algorithm driven nurse led care of hypertension, and nurse prescribers

There is little directly applicable evidence for benefits of nurse involvement in hypertension within the UK National Health Service
Detection, Evaluation, and Treatment of High Blood Pressure. Hypertension 2003;42:1206-52.

5 Inkster M, Montgomery A, Donnan P, MacDonald T, Sullivan F, Fahey T. Organisational factors in relation to control of blood pressure: an observational study. Br J Gen Pract 2005;55:931-7.

6 Phillips LS, Branch WT, Cook CB, Doyle JP, El Kebbi IM, Gallina DL, et al. Clinical inertia. Ann Intern Med 2001;135:825-34.

7 Mancia G, De Backer G, Dominiczak A, Cifkova R, Fagard R, Germano G, et al. 2007 guidelines for the management of arterial hypertension: the Task Force for the Management of Arterial Hypertension of the European Society of Hypertension (ESH) and of the European Society of Cardiology (ESC). Eur Heart J 2007;28:1462-536.

8 National Institute for Health and Clinical Excellence. Hypertension: management of hypertension in adults in primary care: partial update. Royal College of Physicians, 2006.

9 Confederation NHS, British Medical Association. New GMS contract 2003: investing in general practice. British Medical Association/N HS Confederation, 2003.

10 NHS Information Centre. Practice level QOF tables 2008/09-clinical domain-hypertension. 2009. www.ic.nhs.uk/statistics-and-datacollections/supporting-information/audits-and-performance/thequality-and-outcomes-framework/qof-2008/09/data-tables/ practice-level-data-tables.

11 Heneghan C, Perera R, Mant D, Glasziou P. Hypertension guideline recommendations in general practice: awareness, agreement, adoption, and adherence. Br J Gen Pract 2007;57:948-52.

12 Fahey T, Schroeder K, Ebrahim S, Glynn L. Interventions used to improve control of blood pressure in patients with hypertension. Cochrane Database Syst Rev 2005;1:CD005182.

13 Laurant M, Reeves D, Hermens R, Braspenning J, Grol R, Sibbald B. Substitution of doctors by nurses in primary care. Cochrane Database Syst Rev 2005;2:CD001271.

14 Oakeshott P, Kerry S, Austin A, Cappuccio F. Is there a role for nurseled blood pressure management in primary care? Fam Pract 2003;20:469-73.

15 Higgins JPT, Green S. Cochrane handbook for systematic reviews of interventions 5.0.2 [updated September 2009]. Cochrane Collaboration, 2009. www.cochrane-handbook.org.

16 Review Manager (RevMan) [Computer program]. Version 5.0. Copenhagen: Nordic Cochrane Centre, Cochrane Collaboration, 2008.

17 Adams G, Gulliford MC, Ukoumunne OC, Eldridge S, Chinn S, Campbell MJ. Patterns of intra-cluster correlation from primary care research to inform study design and analysis. J Clin Epidemiol 2004;57:785-94.

18 Bebb C, Kendrick D, Coupland C, Madeley R, Stewart], Brown K, et al. A cluster randomised controlled trial of the effect of a treatment algorithm for hypertension in patients with type 2 diabetes. Br J Gen Pract 2007; 57:136-43.

19 Bellary S, O’Hare JP, Raymond NT, Gumber A, Mughal S, Szczepura A et al. Enhanced diabetes care to patients of south Asian ethnic origin (the United Kingdom Asian Diabetes Study): a cluster randomised controlled trial. Lancet 2008;371:1769-76.

20 Jolly K, Bradley F, Sharp S, Smith H, Thompson S, Kinmonth AL, et al. Randomised controlled trial of follow up care in general practice of patients with myocardial infarction and angina: final results of the Southampton heart integrated care project (SHIP). The SHIP Collaborative Group. BMJ 1999;318:706-11.

21 Moher M, Yudkin P, Wright L, Turner R, Fuller A, Schofield T, et al. Cluster randomised controlled trial to compare three methods of promoting secondary prevention of coronary heart disease in primary care. $B M / 2001: 322: 1338$.

22 New JP, Mason JM, Freemantle N, Teasdale S, Wong L, Bruce NJ, et al. Educational outreach in diabetes to encourage practice nurses to use primary care hypertension and hyperlipidaemia guidelines (EDEN): a randomized controlled trial. Diabet Med 2004;21:599-603.

23 O'Hare IP, Raymond NT, Mughal S, Dodd L, Hanif W, Ahmad Y, et al. Evaluation of delivery of enhanced diabetes care to patients of South Asian ethnicity: the United Kingdom Asian Diabetes Study (UKADS). Diabet Med 2004; 21:1357-65.

24 Becker DM, Yanek LR, Johnson WR Jr, Garrett D, Moy TF, Reynolds SS, et al. Impact of a community-based multiple risk factor intervention on cardiovascular risk in black families with a history of premature coronary disease. Circulation 2005;111:1298-304.

25 Bosworth HB, Olsen MK, Dudley T, Orr M, Goldstein MK, Datta SK, et al. Patient education and provider decision support to control blood pressure in primary care: a cluster randomized trial. Am Heart 2009;157:450-6.

26 Artinian NT, Washington OG, Templin TN. Effects of home telemonitoring and community-based monitoring on blood pressure control in urban African Americans: a pilot study. Heart Lung 2001;30:191-9.

National Centre for Social Research. Health survey for England 2003. Department of Health, 2004.

Global burden of hypertension: analysis of worldwide data. Lancet 2005;365:217-23.

4 Chobanian AV, Bakris GL, Black HR, Cushman WC, Green LA, Izzo JL J et al. Seventh report of the Joint National Committee on Prevention, 
27 Woollard J, Burke V, Beilin LJ. Effects of general practice-based nursecounselling on ambulatory blood pressure and antihypertensive drug prescription in patients at increased risk of cardiovascular disease. J Hum Hypertens 2003;17:689-95.

28 Woollard J, Beilin L, Lord T, Puddey I, MacAdam D, Rouse I. A controlled trial of nurse counselling on lifestyle change for hypertensives treated in general practice: preliminary results. Clin Exp Pharmacol Physiol 1995;22:466-8.

29 Artinian NT, Flack JM, Nordstrom CK, Hockman EM, Washington OG, Jen $\mathrm{KL}$, et al. Effects of nurse-managed telemonitoring on blood pressure at 12-month follow-up among urban African Americans. Nurs Res 2007;56:312-22.

30 Rudd P, Miller NH, Kaufman J, Kraemer HC, Bandura A, Greenwald G, et al. Nurse management for hypertension. A systems approach. $\mathrm{Am}$ J Hypertens 2004;17:921-7.

31 Taylor CB, Miller NH, Reilly KR, Greenwald G, Cunning D, Deeter A et al. Evaluation of a nurse-care management system to improve outcomes in patients with complicated diabetes. Diabetes Care 2003;26:1058-63.

32 Garcia-Pena C, Thorogood M, Armstrong B, Reyes-Frausto S, Munoz O. Pragmatic randomized trial of home visits by a nurse to elderly people with hypertension in Mexico. Int J Epidemiol 2001;30:1485-91.

33 Jiang X, Sit JW, Wong TK. A nurse-led cardiac rehabilitation programme improves health behaviours and cardiac physiological risk parameters: evidence from Chengdu, China. J Clin Nurs 2007; 16:1886-97.

34 Lee LL, Arthur A, Avis M. Evaluating a community-based walking intervention for hypertensive older people in Taiwan: a randomized controlled trial. Prev Med 2007;44:160-6.

35 Logan AG, Milne BJ, Achber C, Campbell WP, Haynes RB. Work-site treatment of hypertension by specially trained nurses. A controlled trial. Lancet 1979;2:1175-8.

36 McLean DL, McAlister FA, Johnson JA, King KM, Makowsky MJ, Jones CA, et al. A randomized trial of the effect of community pharmacist and nurse care on improving blood pressure management in patients with diabetes mellitus: study of cardiovascular risk intervention by pharmacists-hypertension (SCRIP-HTN). Arch Intern Med 2008;168:2355-61.

37 Tobe SW, Pylypchuk G, Wentworth J, Kiss A, Szalai JP, Perkins N, et al. Effect of nurse-directed hypertension treatment among First Nations people with existing hypertension and diabetes mellitus: the Diabetes Risk Evaluation and Microalbuminuria (DREAM 3) randomized controlled trial. CMA/ 2006;174:1267-71.

38 Jewell D, Hope J. Evaluation of a nurse-run hypertension clinic in general practice. Practitioner 1988;232:484-7.

39 Campbell NC, Ritchie LD, Thain J, Deans HG, Rawles JM, Squair JL. Secondary prevention in coronary heart disease: a randomised trial of nurse led clinics in primary care. Heart 1998;80:447-52.

40 Hill MN, Han HR, Dennison CR, Kim MT, Roary MC, Blumenthal RS, et al. Hypertension care and control in underserved urban African American men: behavioral and physiologic outcomes at 36 months Am J Hypertens 2003;16:906-13.

41 Kastarinen MJ, Puska PM, Korhonen MH, Mustonen JN, Salomaa VV, Sundvall JE, et al. Non-pharmacological treatment of hypertension in primary health care: a 2-year open randomized controlled trial of lifestyle intervention against hypertension in eastern Finland. J Hypertens 2002;20:2505-12.

42 Mundinger MO, Kane RL, Lenz ER, Totten AM, Tsai WY, Cleary PD, et al. Primary care outcomes in patients treated by nurse practitioners or physicians: a randomized trial. JAMA 2000;283:59-68.
43 Schroeder K, Fahey T, Hollinghurst S, Peters TJ. Nurse-led adherence support in hypertension: a randomized controlled trial. Fam Pract 2005;22:144-51.

44 Denver EA, Barnard M, Woolfson RG, Earle KA. Management of uncontrolled hypertension in a nurse-led clinic compared with conventional care for patients with type 2 diabetes. Diabetes Care 2003;26:2256-60.

45 Guerra-Riccio GM, Artigas Giorgi DM, Consolin-Colombo FM, Barreto-Filho JA, Lopes HF, Fleury Camargo AL, et al. Frequent nurse visits decrease white coat effect in stage III hypertension. Am J Hypertens 2004;17:523-8.

46 Ko GT, Li JK, Kan EC, Lo MK. Effects of a structured health education programme by a diabetic education nurse on cardiovascular risk factors in Chinese type 2 diabetic patients: a 1-year prospective randomized study. Diabet Med 2004;21:1274-9.

47 Litaker D, Mion L, Planavsky L, Kippes C, Mehta N, Frolkis J. Physiciannurse practitioner teams in chronic disease management: the impact on costs, clinical effectiveness, and patients' perception of care. J Interprof Care 2003;17:223-7.

48 New JP, Mason JM, Freemantle N, Teasdale S, Wong LM, Bruce NJ, et al. Specialist nurse-led intervention to treat and control hypertension and hyperlipidemia in diabetes (SPLINT): a randomized controlled trial. Diabetes Care 2003;26:2250-5.

49 Tonstad S, Alm CS, Sandvik E. Effect of nurse counselling on metabolic risk factors in patients with mild hypertension: a randomised controlled trial. Eur J Cardiovasc Nurs 2007;6:160-4.

50 McHugh F, Lindsay GM, Hanlon P, Hutton I, Brown MR, Morrison C, et al. Nurse led shared care for patients on the waiting list for coronary artery bypass surgery: a randomised controlled trial. Heart 2001;86:317-23.

51 Bengtson A, Drevenhorn E. The nurse's role and skills in hypertension care: a review. Clin Nurse Spec 2003;17:260-8.

52 Roland M, Torgerson DJ. Understanding controlled trials: what are pragmatic trials? BMJ 1998;316:285.

53 Sol BG, van der Bijl JJ, Banga JD, Visseren FL. Vascular risk management through nurse-led self-management programs. J Vasc Nurs 2005;23:20-4.

54 Page T, Lockwood C, Conroy-Hiller T. Effectiveness of nurse-led cardiac clinics in adult patients with a diagnosis of coronary heart disease. International Journal of Evidence-Based Healthcare 2005;3:2-26.

55 Kinnersley P, Anderson E, Parry K, Clement J, Archard L, Turton P, et a Randomised controlled trial of nurse practitioner versus general practitioner care for patients requesting "same day" consultations in primary care. BMJ 2000;320:1043-8.

56 Dierick-van Daele AT, Steuten LM, Metsemakers JF, Derckx EW, Spreeuwenberg C, Vrijhoef HJ. Economic evaluation of nurse practitioners versus GPs in treating common conditions. Br J Gen Pract 2010;60:e28-e35.

57 Houston MC. Handbook of hypertension. Wiley-Blackwell, 2009.

58 Cook NR, Cohen J, Hebert PR, Taylor JO, Hennekens CH. Implications of small reductions in diastolic blood pressure for primary prevention. Arch Intern Med 1995;155:701-9.

59 Neal B, MacMahon S, Chapman N. Effects of ACE inhibitors, calcium antagonists, and other blood-pressure-lowering drugs: results of prospectively designed overviews of randomised trials. Blood Pressure Lowering Treatment Trialists' Collaboration. Lancet 2000;356:1955-64

Accepted: 11 June 2010 